\title{
CONGENITAL PARALYTIC ILEUS IN A PREMATURE BABY AS A COMPLICATION OF HEXAMETHONIUM BROMIDE THERAPY FOR TOXAEMIA OF PREGNANCY
}

\author{
BY \\ JEAN L. HALLUM and W. L. F. HATCHUEL \\ From Sorrento Maternity Hospital, Birmingham
}

(RECEIVED FOR PUBLICATION MARCH 10, 1954)

The increasingly frequent use of the ganglionic blocking agents in the treatment of hypertensive states makes it essential that all toxic effects be reported so that the dangers may be given due consideration. This case of paralytic ileus in a premature baby after the mother had been treated during pregnancy with hexamethonium bromide is therefore reported. To the best of our knowledge only three cases in newborn babies have been recorded (Morris, 1953).

\section{The Mother}

Mrs. G., a primigravida aged 32 years, was admitted to hospital on September 3 during the thirtieth week of pregnancy. She had severe pre-eclampsia. Table 1 is a summary of the clinical findings during the preceding weeks of pregnancy.
On October 5 a caesarean section was performed, hexamethonium bromide having been given up to and including that day. The anaesthetics used were thiopentone, nitrous oxide, oxygen and ether. The indications for caesarean section were (1) progressive deterioration in the patient's condition as evidenced by increasing albuminuria and oliguria with persistent generalized oedema, in spite of slight lowering in the mean blood pressure readings (2) apparent cessation of foetal growth; (3) cervical rigidity contraindicating surgical induction of labour.

The baby, a girl, had a birth weight of $3 \mathrm{lb} .4 \mathrm{oz}$., length of $16 \frac{1}{2}$ in., head circumference of $11 \frac{1}{2}$ in. at 34 weeks' gestation.

\section{The Baby}

Day 1. At birth, the baby was cyanosed. An unusually large quantity of liquor was aspirated from the

TABLE 1

CLINICAL FINDING IN FIRST 29 WEEKS OF PREGNANCY

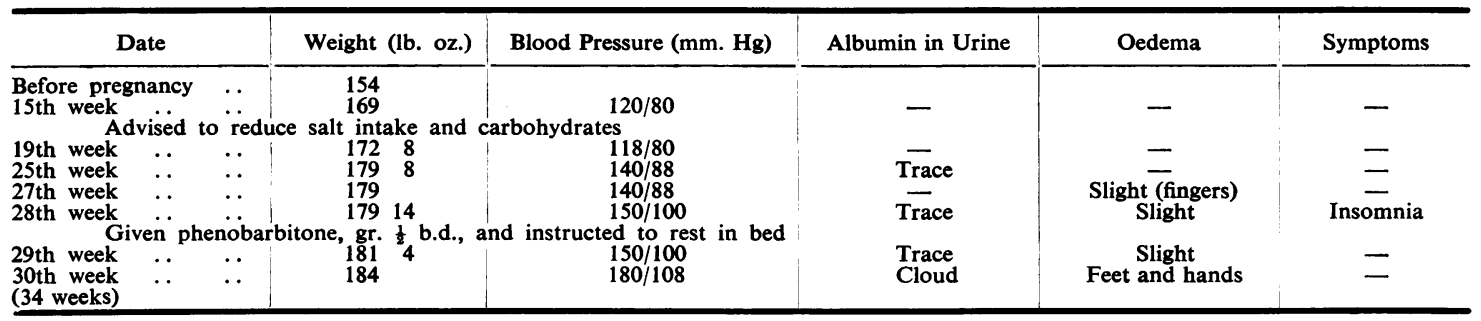

After admission she was treated in bed at complete rest. Sedation, ammonium chloride, and a short course of 'veriloid' produced no appreciable improvement. The blood pressure on September 17, 1953, i.e., at $31 \frac{1}{2}$ weeks, was $170 / 118 \mathrm{~mm}$. $\mathrm{Hg}$ and in addition there was generalized oedema of the limbs, body and face, and $2 \mathrm{~g}$. albumin (Esbach) in the urine. Accordingly, it was decided to start a course of hexamethonium bromide. A test dose of $25 \mathrm{mg}$. was given subcutaneously and followed by $50 \mathrm{mg}$. subcutaneously six hourly.

Table 2 summarizes the patient's condition during the following two weeks.
TABLE 2

CLINICAL FINDINGS IN LAST TWO WEEKS OF PREGNANCY

\begin{tabular}{|c|c|c|c|c|}
\hline \multirow[b]{2}{*}{ Date } & \multicolumn{2}{|c|}{ Blood Pressure (mm. Hg) } & \multirow{2}{*}{$\begin{array}{c}\text { Urinary } \\
\text { Albumin (mg. } \\
\text { Esbach) }\end{array}$} & \multirow{2}{*}{ Oedema } \\
\hline & Highest & Lowest & & \\
\hline \multirow{2}{*}{$\begin{array}{l}17.9 .53 \\
\left(31 \frac{1}{2} \text { weeks) }\right. \\
20.9 .53 \\
25.9 .53 \\
30.9 .53 \\
4.10 .53\end{array}$} & $170 / 118$ & $148 / 110$ & 2 & $++t$ \\
\hline & $\begin{array}{l}176 / 120 \\
160 / 114 \\
158 / 108 \\
140 / 100\end{array}$ & $\begin{array}{l}148 / 106 \\
134 / 100 \\
134 / 94 \\
130 / 90\end{array}$ & $\begin{array}{l}2 \\
3 \\
3 \frac{3}{4} \\
5 \frac{1}{2}\end{array}$ & $\begin{array}{l}+t+ \\
++t \\
++t \\
++t\end{array}$ \\
\hline
\end{tabular}


pharynx and stomach, and with the baby nursed head down liquor continued to trickle out for a further half-hour.

Thereafter, the baby was transferred to the Premature Baby Unit and nursed in an 'isolette' incubator. The baby's condition was now fairly good, though the cry was poor, and there remained slight generalized cyanosis.

Day 2. The general condition had improved, but the baby was still lethargic. Generalized oedema of the limbs developed and lasted for a week.

Day 3. The abdomen was distended, and the skin around the umbilicus was slightly red. Suspecting an early umbilical infection, treatment with intramuscular penicillin and soluthiazole was begun. That afternoon, the first glucose water feed was given. Later the baby vomited a brown mucoid material.

Day 4. The first meconium stool was passed. The baby's general condition and state of hydration remained good. The baby was fed on diluted breast milk, but feeds were stopped in the evening on account of gross abdominal distension and 1 in 5 normal saline was injected subcutaneously to maintain hydration.

Day 5. The abdominal distension had increased, and a very resonant percussion note could be elicited over the entire abdomen. A stomach wash-out was performed, and gastric flatus and some brown material similar to that vomited on the third day were removed. After the wash-out the abdominal distension diminished considerably, though only temporarily.

That evening, a bowel wash-out with half normal saline produced a black cast of inspissated meconium, approximately 3 in. long and $\frac{1}{3}$ in. in diameter.

Day 6. Abdominal distension was still gross, although a very small meconium stool had been passed spontaneously during the night. Radiographic screening showed gross gaseous distension of the entire gut without signs of organic obstruction. Peristalsis, while present, was only sluggish.

Small tube feeds were begun again and later in the day tube feeding was replaced by bottle feeding as the baby began to suck.

Day 7. No change.

Day 8. The baby vomited twice only. Abdominal distension continued. The baby was placed in a sitting position and kept like that for the next two days but with little noticeable effect. The stools became larger and greener. It was not until the thirteenth day that the first 'changing stool' appeared. Feeds were being retained but the abdomen remained distended.

Day 13. Abdominal distension began to diminish. The haemoglobin was $14.0 \mathrm{~g}$. \%. A transfusion of $30 \mathrm{ml}$. whole blood was given.
Days 16-21. The baby became far more active, stools were assuming a more normal appearance, and a gain in weight was recorded. On the twenty-first day an entirely normal stool was passed and since then there has been an uninterrupted gain in weight and apparently normal development.

\section{- Discussion}

The toxic effects of hexamethonium bromide are numerous, ranging from symptomatic discomfort, such as blurring of vision, dry mouth, constipation (Morrison, 1953; Mackey and Shaw, 1951; Turner, 1950) to attacks of postural hypotension, resulting in cerebral thrombosis and cerebral haemorrhage (Hirson and Kelsall, 1951) and fatal paralytic ileus (Bourne and Hosford, 1951).

The effects on the foetus and newborn infant in toxaemic mothers has been studied by Turner (1952), Mulcahy (1952) and Morris (1953). Turner and Mulcahy reported that they observed no harmful effects on the newborn baby, but Morris reporting on the use of hexamethonium bromide in 10 toxaemic mothers reported complications in three and possibly four of the issue. Two babies died with symptoms of paralytic ileus. There was a 20-hour delay in the passage of the first meconium stool in the third baby, and a fourth died with widespread purulent bronchopneumonia which Morris suggested may have been due to reduced bronchial secretion favouring respiratory infection. In his tenth case he studied the liquor levels of hexamethonium bromide in an anencephalic monster. He found that there was a rise in the level in the liquor, which continued even after administration of the drug was stopped, and suggested that this proved the excretion of the drug in the foetal urine. (However, since an anencephalic monster cannot swallow (Taussig, 1927) the theory that the drug normally concentrates to the degree he quotes is open to serious doubt.)

Young (1952) has studied hexamethonium bromide levels in pregnant rabbit does and showed free passage of the drug across the placental barrier. The drug persisted in the liquor for many days after the last dose had been given. It is probable, therefore, that in the case recorded here the continued administration of the hexamethonium bromide to the mother to the time of the caesarean section had resulted in a high foetal blood level of the drug. This in turn had caused lethargy and paralytic ileus, the symptoms of which abated as the drug was excreted from the baby's body.

Morrison and Paton (1953) studying the effects of parenteral administration of hexamethonium bromide on normal individuals in relation to its 
concentration in the plasma, found that 'the drug is evenly distributed throughout the extracellular fluid' and that their calculations were 'compatible with its excretion by glomerular filtration'. This would explain the prolonged symptoms in the case recorded here since glomerular filtration in premature babies is very poor (Young, Hallum and McCance, 1941). The oedema neonatorum occurring in this baby would also support this hypothesis (Hallum, 1941).

McMichael (1952) states that vomiting and paralytic ileus seem more likely to occur when hexamethonium bromide is given orally. The fact that the foetus is constantly swallowing its own liquor would explain why this baby developed paralytic ileus while the mother, who was receiving hexamethonium bromide parenterally, had no disturbance of gastro-intestinal function. Details of the mother's history will be recorded elsewhere, but it may be mentioned here that on the day following the caesarean section she had a severe hypotensive attack following a dose of $50 \mathrm{mg}$. of hexamethonium bromide.

\section{Summary}

A case is recorded of transient paralytic ileus of congenital origin following treatment of the mother with daily doses of hexamethonium bromide (50 mg. q.i.d.) for 18 days up to and including the time of delivery of the baby. The baby failed to pass an appreciable quantity of meconium until a bowel wash-out was done on the fifth day. Peristalsis was diminished and there was gaseous distension of the entire gut lasting from shortly after birth until the third week of life. The character of the stools changed only during the second week, and normal size and consistency was assumed only at the end of the third week.

We are grateful to Dr. V. Mary Crosse in whose unit this baby was treated, and to Dr. L. M. Masterman who saw the baby in her absence. We also thank Dr. Astley for screening this baby.

\section{REFERENCES}

Bourne, G. and Hosford, J. (1951). Lancet, 1, 527.

Hallum, J. L. (1941). M.D. Thesis, Univ. St. Andrews.

Hirson, C. and Kelsall, A. R. (1951). Lancet, 1, 585.

Mackey, W. A. and Shaw, G. B. (1951). Brit. med. J., 2, 259

McMichael, J. (1952), Ibid., 1, 933.

Morris, N.'(1953). Lancet, 1, 322.

Morrison, B. (1953). Brit. med. J., 1, 1291.

Morrison, B. (1953). Brit. med. J., 1, 1291. 1299

Mulcahy, R. (1952). J. Irish med. Ass., 31, 205.

Taussig, F. J. (1927). Amer. J. Obstet. Gynec., 14, 505

Turner, R. (1950). Lancet, 2, 353.

- (1951). Ibid., 1, 408

Young, I. M. (1952). J. Physiol., Lond., 116, 4 P.

Young, W. F., Hallum, J. L. and McCance, R. A. (1941). Archives of Disease in Childhood, 16, 243. 